Research Article

\title{
Circularly Polarized Dielectric Resonator Antenna Arrays with Fractal Cross-Slot-Coupled DRA Elements
}

\author{
Jia-Hong Lin, Wen-Hui Shen, Zhi-Dong Shi, and Shun-Shi Zhong \\ School of Communication and Information Engineering, Shanghai University, Shanghai 200072, China \\ Correspondence should be addressed to Jia-Hong Lin; reallylin@hotmail.com
}

Received 4 July 2017; Revised 28 September 2017; Accepted 12 October 2017; Published 14 November 2017

Academic Editor: Piotr Samczynski

Copyright (C) 2017 Jia-Hong Lin et al. This is an open access article distributed under the Creative Commons Attribution License, which permits unrestricted use, distribution, and reproduction in any medium, provided the original work is properly cited.

\begin{abstract}
In the design of circularly polarized (CP) dielectric resonator antenna (DRA) arrays, the regular-shaped DRAs with simple feeding configurations are mostly used as array elements to make the design procedure more efficient. However, such array element DRA usually achieves only about $6 \%$ axial ratio (AR) bandwidth. In this paper, a CP DRA element coupled by a fractal cross-slot which can radiate efficiently and excite the rectangular DRA simultaneously is considered. By adjusting the dimensions of the fractal cross-slot properly, the resonances of the fractal cross-slot and the dielectric resonator can be merged to obtain a wider AR bandwidth. Based on the proposed fractal cross-slot-coupled CP DRA element, two different CP DRA arrays are designed: a wideband CP DRA array and a low-sidelobe-level (SLL) CP DRA array. The designed DRA arrays are fabricated and measured, and structures and performances of the arrays are presented and discussed.
\end{abstract}

\section{Introduction}

Over the last decades, DRAs have become more and more popular because of their high radiation efficiency due to the absence of conductor as well as surface wave loss. On the other hand, DRAs can be fed by various feeding techniques, such as the microstrip line feed, the coaxial probe feed, the coplanar waveguide feed, and the aperture coupling feed.

Initial studies of DRAs were concentrated on linearly polarized (LP) designs. In 1985, Haneishi and Takazawa [1] designed the first CP DRA by truncating two opposite corners of a rectangular DRA, and since then many designs of CP DRAs have been proposed. Nowadays, most designs of CP DRA arrays are based on the sequential feeding technique which was proposed by Huang to generate the $\mathrm{CP}$ array with LP elements [2]. Moreover, three different kinds of microstrip feeding network for sequential feeding technique are studied in [3], and the hybrid ring feeding network shows a better performance than the parallel feeding network and the series one.

Except for the performance of feeding network, the performance of CP DRA array will also be affected by the array element. Several techniques have been proposed to enhance the axial ratio (AR) bandwidth of the single DRA, such as multiple-feed techniques [4-6], traveling wave excitation [7, 8], and novel DRA geometries [9-11]. However, such designs are not very suitable in the design of DRA array. The multiple-feed designs are complicated to implement because they need a complex feeding network. The lumped resistance in traveling wave excitation will cause a decrease in the radiation efficiency. And compared with the novel DRA geometries, regular-shaped DRAs can make the design procedure more efficient because their resonant frequencies can be predicted easily by the dielectric waveguide model (DWM) method [12].

For these reasons cited above, most designers prefer to use regular-shaped DRAs (e.g., rectangular, cylindrical, and elliptical DRAs) and simple feeding configurations (e.g., single microstrip feed and slot aperture feed) in the design of DRA array. Especially, to avoid the parasitic radiation from feeding network affecting the radiation pattern of the array, the slot aperture feed is mostly widely used. In [13], a cross-slot-coupled cylindrical DRA with 5.6\% effective AR bandwidth $\left(S_{11}<-10 \mathrm{~dB}\right.$ and $\left.\mathrm{AR}<3 \mathrm{~dB}\right)$ is used as the array element in the CP DRA array. In [3], the slot-coupled elliptical DRA with 5\% effective AR bandwidth is used as the array element. It can be seen that such regular-shaped DRAs with 


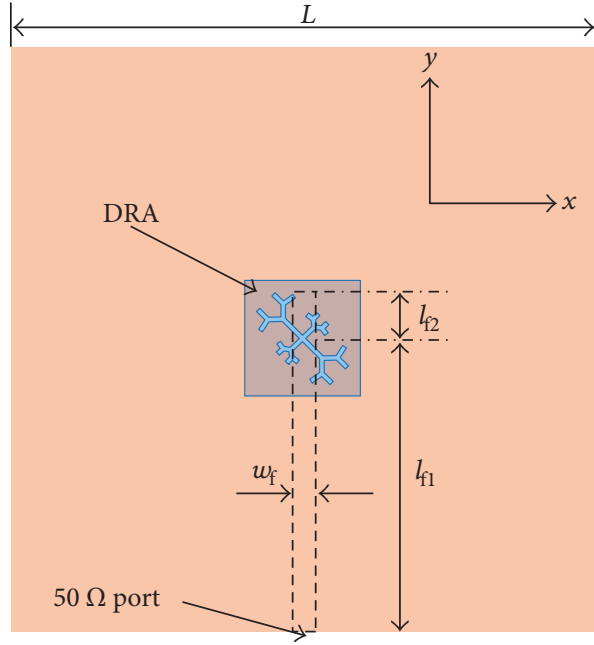

(a)
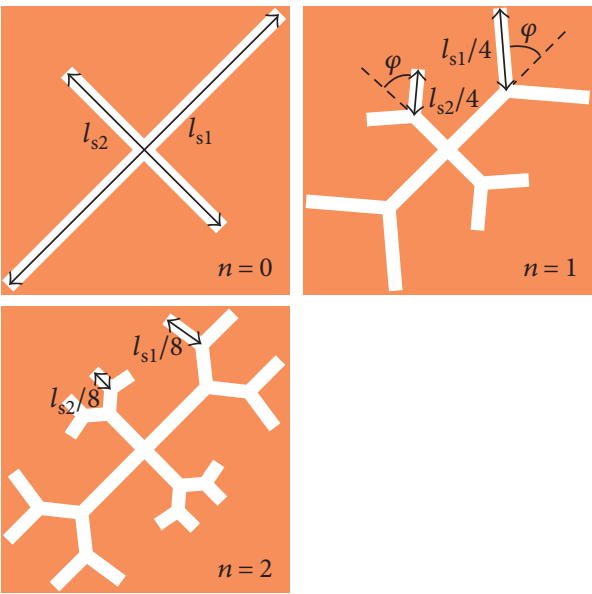

(b)

Figure 1: Antenna structure. (a) Top view and (b) structures of the fractal cross-slot with iterations $n=0,1$, and 2 .

simple feeding configurations usually suffer from a narrow effective $\mathrm{AR}$ bandwidth. To enhance the effective $\mathrm{AR}$ bandwidth of the array element, a structure of two-layered substrates is used in the design of a cross-slot-coupled rectangular DRA, and corresponding effective AR bandwidth of the array element is enhanced to about $9 \%$ [14].

In this paper, a CP rectangular DRA element is designed using a relative permittivity $\varepsilon_{\mathrm{r}}=8.9$, which has an effective AR bandwidth of about $12 \%$ by introducing a fractal crossslot on the ground plane under the resonator. The proposed DRA element has a simple structure without dual feeds or two-layered substrates, and the mutual coupling between two elements of the proposed structure is found to be small although the distance between the elements is relatively small. Based on the fractal cross-slot-coupled CP DRA element, a wideband CP DRA array and a low-sidelobe-level CP DRA array are designed and studied. The arrays are fabricated and their measured results are verified with the simulated one.

\section{Design of the Array Element}

2.1. Antenna Structure. The structure of the array element is shown in Figure 1. A Rogers RT/duroid 5880 (tm) substrate with relative permittivity $\varepsilon_{\mathrm{r}}=2.2$, dielectric loss tangent 0.0009 , and thickness $=0.508 \mathrm{~mm}$ is used in the design, and the length and width of the substrate are both $50 \mathrm{~mm}$. A ceramic cube with relative permittivity $\varepsilon_{\mathrm{r}}=8.9$, length $=9.8 \mathrm{~mm}$, width $=9.8 \mathrm{~mm}$, and height $=9.1 \mathrm{~mm}$ is mounted on the center of the ground plane, and beneath the ceramic cubic is a fractal cross-slot etched on the ground plane. The $50 \Omega$ microstrip line on the bottom side of the substrate has a length of $l_{\mathrm{f} 1}+l_{\mathrm{f} 2}$ and a width of $w_{\mathrm{f}}$. As shown in Figure 1(a), $l_{\mathrm{f} 1}$ is the distance between the $50 \Omega$ port and the center of the ceramic cubic, and $l_{\mathrm{f} 2}$ is the distance between the center of the ceramic cubic and the terminal of the $50 \Omega$ microstrip line.

2.2. Effect of the Fractal Cross-Slot. Figure 1(b) shows the structures of the fractal cross-slot with iterations $n=0,1$, and 2. The fractal structure is developed from the ordinary cross-slot $(n=0)$ which has lengths of $l_{\mathrm{s} 1}, l_{\mathrm{s} 2}\left(l_{\mathrm{s} 2}=k_{\mathrm{s}} \times l_{\mathrm{s} 1}\right)$ and a width of $w_{s}$. In the iterative procedure, the width of the slot is constant, and the iterative angle and iterative length coefficient are $\varphi$ and 0.5 , respectively.

To explain the effect of the fractal structure, simulated $S_{11}$ and ARs of the array element with different values of $n$ and $l_{\mathrm{s} 1}$ are presented in Figure 2. According to the DWM method, the theoretical resonant frequencies of $\mathrm{TE}_{111}^{x}$ and $\mathrm{TE}_{111}^{y}$ modes in the proposed rectangular DRA are both $6.67 \mathrm{GHz}$. To obtain the $\mathrm{CP}$ radiation, these two modes should be excited simultaneously in the DRA. Of course, the practical resonant frequency in the DRA will also be affected by the feeding structure. Generally speaking, practical resonant frequencies of $\mathrm{TE}_{111}^{x}$ and $\mathrm{TE}_{111}^{y}$ modes will not be identical. As long as these two modes are excited at the adjacent frequency band, the effective $\mathrm{CP}$ radiation can be obtained. However, the AR bandwidth due to the resonances of the dielectric resonator is usually narrow. To enhance the AR bandwidth, dimensions of the crossslot need to be adjusted suitably, so that the resonances of the cross-slot and the dielectric resonator can be merged to obtain a wider AR bandwidth, and then, the corresponding DRA will be a hybrid-radiation CP DRA.

However, when the ordinary cross-slot $(n=0)$ is used, such hybrid-radiation CP DRA is difficult to be obtained. As shown in Figure 2, when $n=0$ and $l_{\mathrm{s} 1}=7.9 \mathrm{~mm}$, two resonant frequencies can be found in the $S_{11}$ curve. The lower resonant frequency (about $7.2 \mathrm{GHz}$ ) is due to the resonance of the DRA, and the higher one (about $8.6 \mathrm{GHz})$ is due to the resonance of the slot. In fact, the $\mathrm{TE}_{111}^{x}$ and $\mathrm{TE}_{111}^{y}$ modes in the DRA are not effectively excited here. According to the DWM method, the resonant frequency at $7.2 \mathrm{GHz}$ is due to the $\mathrm{TE}_{111}^{Z}$ mode in the DRA (the theoretical resonant frequency of $\mathrm{TE}_{111}^{z}$ mode is about $7.4 \mathrm{GHz}$ ). Besides the ineffective excitation of $\mathrm{TE}_{111}^{x}$ and $\mathrm{TE}_{111}^{y}$ modes, the resonant frequency of the slot is too far away from that of the DRA. 


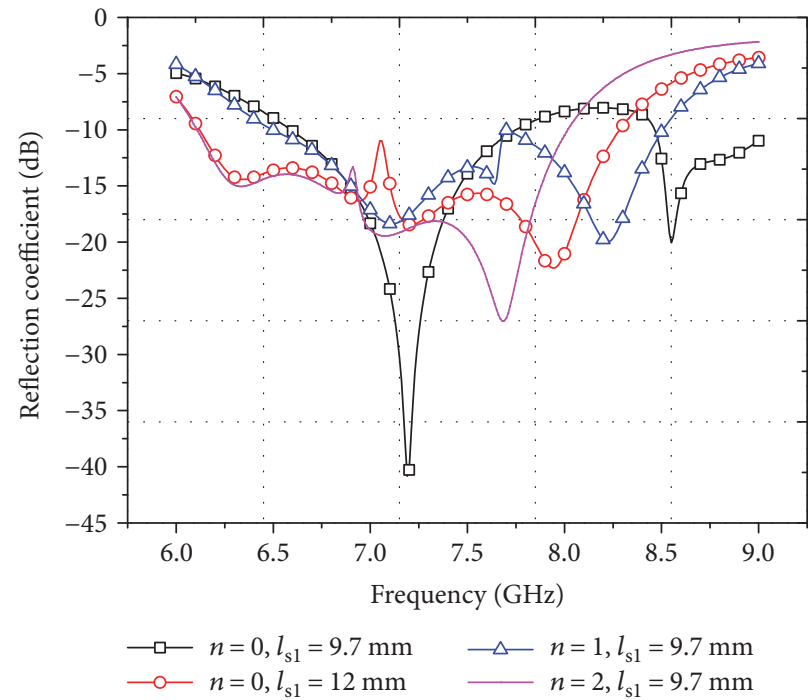

(a)

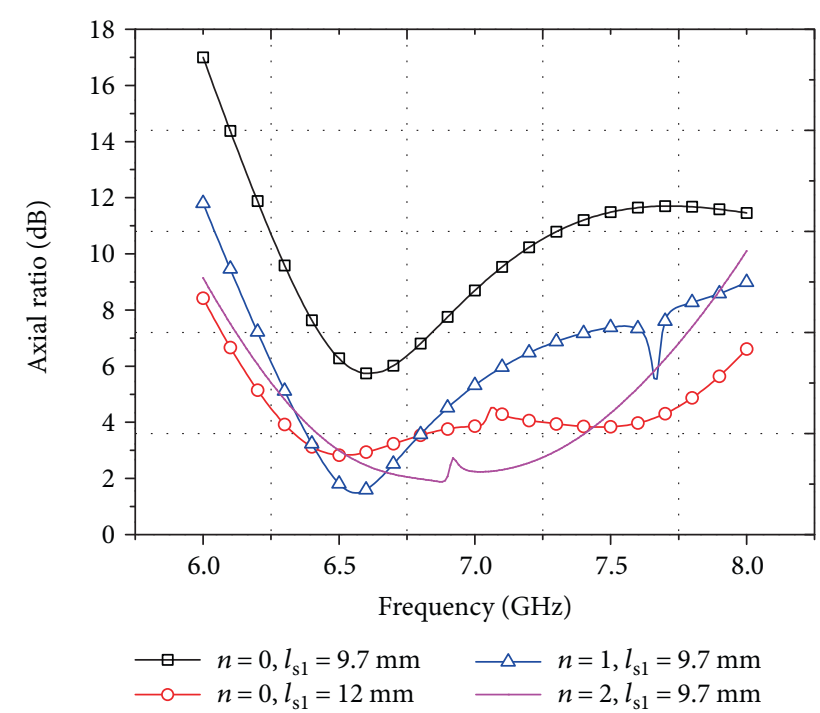

(b)

FIgURe 2: Simulated results of the DRA with different values of $n$ and $l_{\mathrm{s} 1}$. (a) Reflection coefficient and (b) axial ratio $\left(w_{\mathrm{f}}=1.52 \mathrm{~mm}\right.$, $l_{\mathrm{f} 1}=25 \mathrm{~mm}, l_{\mathrm{f} 2}=4 \mathrm{~mm}, w_{\mathrm{s}}=0.4 \mathrm{~mm}, k_{\mathrm{s}}=0.57$, and $\left.\varphi=500\right)$.

To effectively excite the $\mathrm{TE}_{111}^{x}$ and $\mathrm{TE}_{111}^{y}$ modes and lower the resonant frequency of the slot, the simplest method is to increase the value of $l_{\mathrm{s} 1}$. By simulation, we found that the $\mathrm{TE}_{111}^{x}$ and $\mathrm{TE}_{111}^{y}$ modes can be most effectively excited when $l_{\mathrm{s} 1}=12 \mathrm{~mm}$. At this time, the resonant frequencies of the above two modes are about $6.4 \mathrm{GHz}$ and $6.8 \mathrm{GHz}$, and resonant frequencies of two orthogonal modes in the slot can be lowered to $7.2 \mathrm{GHz}$ and $7.9 \mathrm{GHz}$, as shown in Figure 2(a). In this situation, the corresponding CP bands of DRA and slot are found to be around $6.5 \mathrm{GHz}$ and $7.5 \mathrm{GHz}$, respectively. However, according to Figure 2(b), we can find that these two CP bands are also too far away from each other to be merged.

Compared with the ordinary cross-slot, the fractal structure can lower the resonant frequency of the slot more efficiently. When the second iteration $(n=2)$ is used, the resonant frequencies of $\mathrm{TE}_{111}^{x}$ and $\mathrm{TE}_{111}^{y}$ modes are also about $6.4 \mathrm{GHz}$ and $6.8 \mathrm{GHz}$, but resonant frequencies of two orthogonal modes in the slot are further lowered to $7.0 \mathrm{GHz}$ and $7.6 \mathrm{GHz}$. In this situation, CP bands of DRA and slot are found to be well merged, which can effectively enhance the AR bandwidth of the array element.

2.3. Simulated Results. In our design, the parameters of the array element are optimized by the FEM-based commercial software HFSS, and the final parameters of the array element are as follows: $w_{\mathrm{f}}=1.52 \mathrm{~mm}, l_{\mathrm{f} 1}=25 \mathrm{~mm}, l_{\mathrm{f} 2}=4 \mathrm{~mm}$, $l_{\mathrm{s} 1}=9.7 \mathrm{~mm}, w_{\mathrm{s}}=0.4 \mathrm{~mm}, k_{\mathrm{s}}=0.57$, and $\varphi=50^{\circ}$.

Figure 3 is the simulated AR and $S_{11}$ of the array element. The impedance bandwidth of the array element is $26.8 \%$ (from 6.12 to $8.01 \mathrm{GHz}$ ), and the $3 \mathrm{~dB} \mathrm{AR}$ bandwidth is $11.9 \%$ (from 6.49 to $7.31 \mathrm{GHz}$ ). Compared with the results in $[3,13]$ and $[14]$, the proposed array element coupled by the fractal cross-slot can achieve the widest effective AR bandwidth (11.9\%, from 6.49 to $7.31 \mathrm{GHz})$.

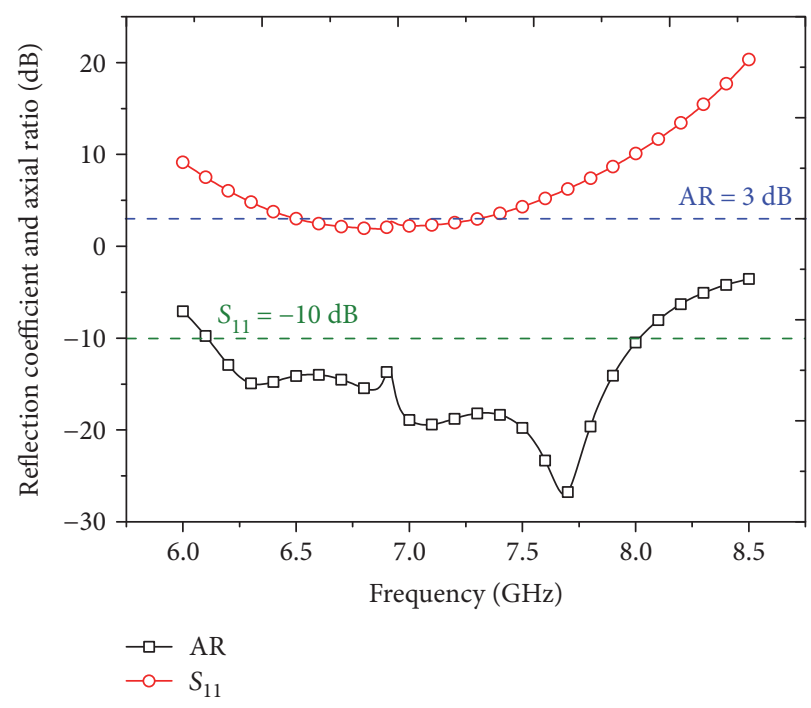

FIgURE 3: Simulated AR and $S_{11}$ of the array element.

Figure 4 is the simulated radiation patterns across the effective AR bandwidth. It can be seen that the radiation patterns are stable across the effective AR bandwidth. Moreover, the radiation pattern has no sidelobe in the upper half space at every frequency, and the maximum radiation happens at $\theta=0^{\circ}$ and $\varphi=0^{\circ}$, which can ensure the design of a lowsidelobe-level array. The left-hand circular polarization (LHCP) gain at $6.5 \mathrm{GHz}, 6.75 \mathrm{GHz}, 7.0 \mathrm{GHz}$, and $7.25 \mathrm{GHz}$ are $7.16 \mathrm{dBi}, 7.02 \mathrm{dBi}, 6.61 \mathrm{dBi}$, and $6.33 \mathrm{dBi}$, respectively.

Since we are proposing the proposed fractal cross-slot coupled DRA for array applications, the mutual coupling between two array elements is studied. The positions of two DRAs in Figures 5(a) and 5(b)are roughly equal to that in a sequential feeding network and a series feeding network which will be used in our design, respectively. 


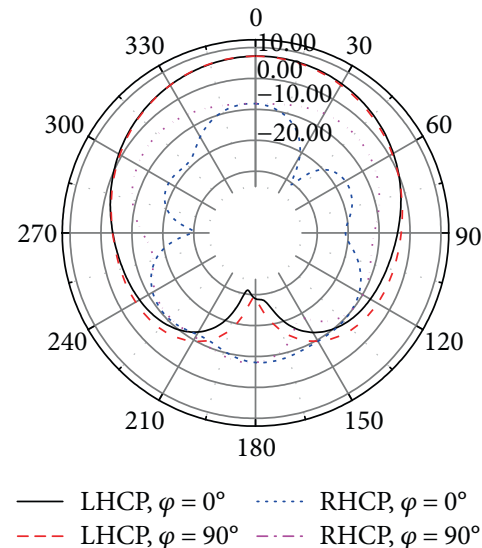

(a)

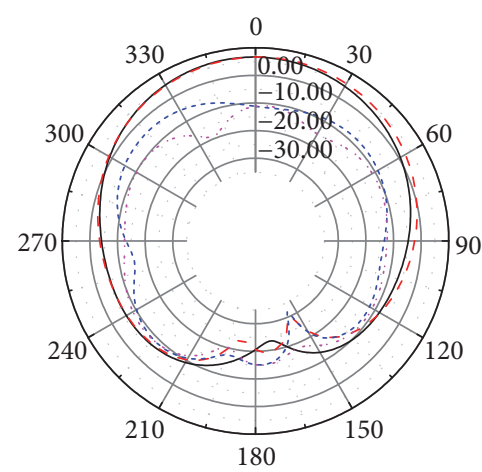

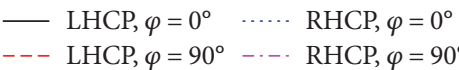

(c)

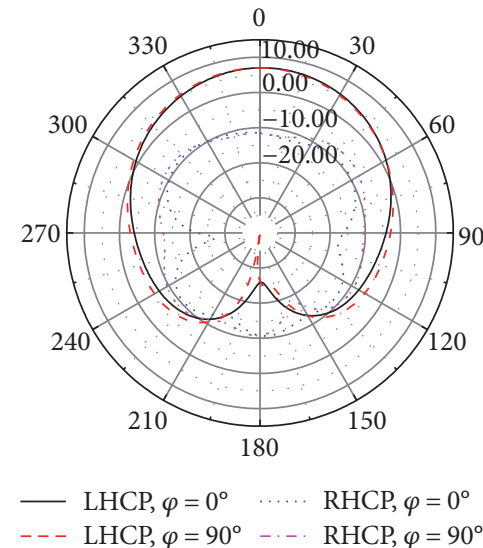

(b)

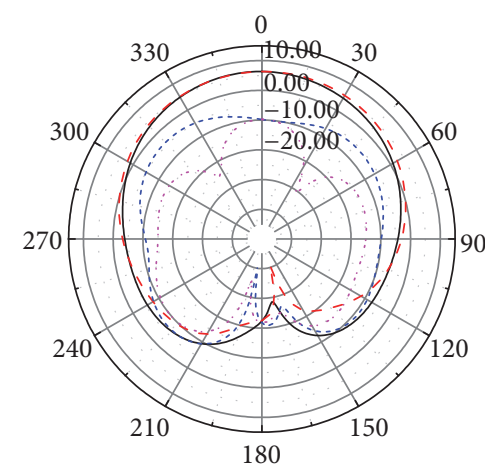

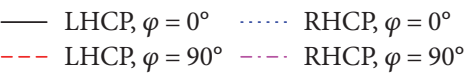

(d)

Figure 4: Simulated radiation patterns of the array element. (a) $6.5 \mathrm{GHz}$, (b) $6.75 \mathrm{GHz}$, (c) $7.0 \mathrm{GHz}$, and (d) $7.25 \mathrm{GHz}$.

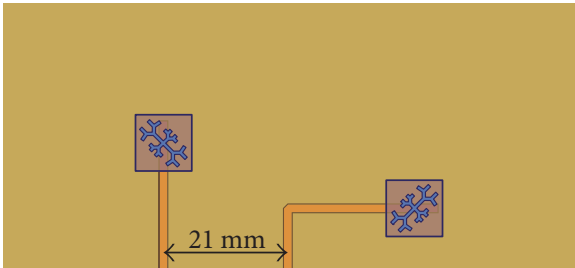

(a)

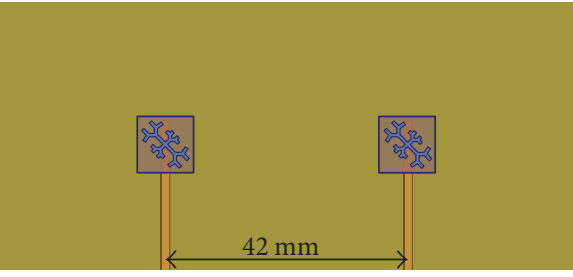

(b)

FIGURE 5: Drawings of two array elements. (a) In a sequential feeding network and (b) in a series feeding network.

The simulated port mutual coupling is shown in Figure 6. The maximum mutual coupling between two elements is lower than $-20 \mathrm{~dB}$, which shows a good isolation between array elements.

\section{Design of the Wideband CP DRA Array}

3.1. Antenna Structure. The structure of the proposed $2 \times 2$ wideband CP DRA array is shown in Figure 7. The length $l$ and width $w$ of the substrate are $100 \mathrm{~mm}$ and $84 \mathrm{~mm}$, respectively. In our design, the hybrid ring feeding network for sequential feeding technique is used, and details of the feeding network designs and analyses can be found in [3].
To get the best performance of the DRA array, parameters of the array are optimized by HFSS. In the design of the array element, the distance between the center of the DRA and the $50 \Omega$ port is $l_{\mathrm{f} 1}=25 \mathrm{~mm}$. In fact, the value of $l_{\mathrm{f} 1}$ in the array element is decided by dimensions of the substrate. For the array element, a large enough substrate is needed to guarantee the performance of the DRA (mainly the radiation pattern and AR), which means that the value of $l_{\mathrm{f} 1}$ cannot be too small. But in the design of the array, the substrate is much larger than that in the array element, which can ensure the performance of the DRA array. In this situation, a smaller value of $l_{\mathrm{f} 1}$ can be selected to accelerate the simulation without degenerating the performance of the array. 


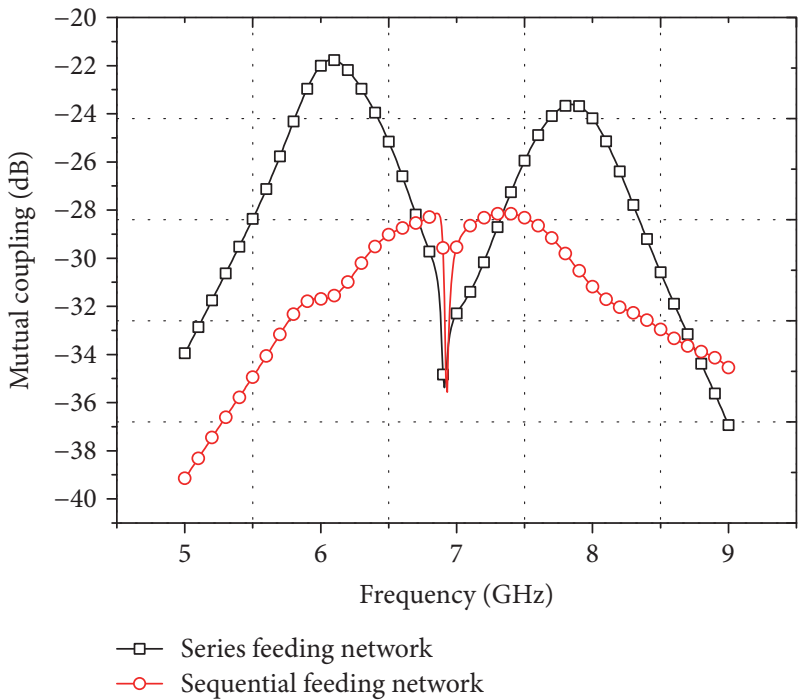

FIGURE 6: Simulated mutual coupling between two array elements.

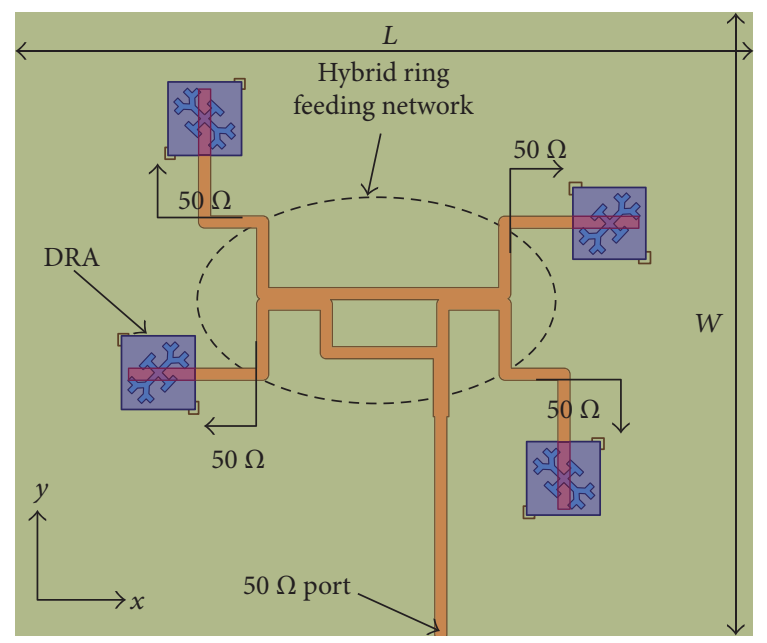

FIGURE 7: Structure of the proposed wideband CP DRA array.

Besides the value of $l_{\mathrm{f} 1}$, dimensions of the fractal crossslot are also optimized in the design, and we find that value of $w_{\mathrm{s}}$ can affect the array more than other parameters.

3.2. Discussion of the Effect of $w_{s}$. Figure 8 shows the effect of $w_{\mathrm{s}}$ on AR of the DRA array. When $w_{\mathrm{s}}$ increases, the curve of $\mathrm{AR}$ is found to move to the higher frequency band, and the $3 \mathrm{~dB}$ AR bandwidth is enhanced due to a lower AR over the frequency band above $8 \mathrm{GHz}$. When $w_{\mathrm{s}}=1.2 \mathrm{~mm}$, the widest $3 \mathrm{~dB}$ AR bandwidth can be obtained. This is an interesting conclusion, which means that the value of $w_{\mathrm{s}}$, which can lead the widest $3 \mathrm{~dB}$ AR bandwidth in the array, is very different from that in the array element.

To explain this problem more clearly, the effect of $w_{\mathrm{s}}$ on the AR of the array element is presented in Figure 9. It is true that the widest $3 \mathrm{~dB}$ AR bandwidth can be obtained when $w_{\mathrm{s}}=0.4 \mathrm{~mm}$. However, when $w_{\mathrm{s}}=0.4 \mathrm{~mm}$ is used, AR of the array element will increase quickly with the increase of

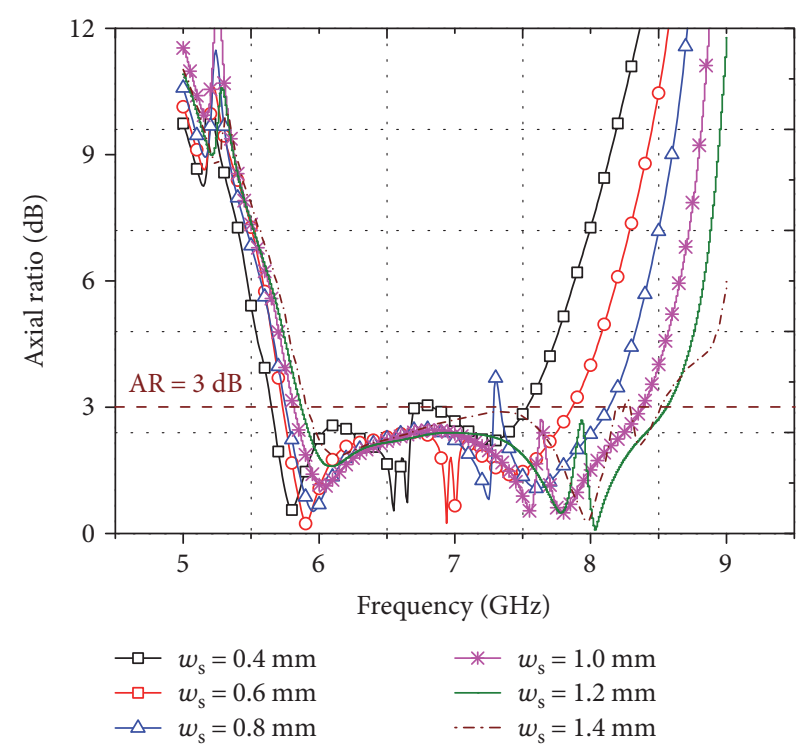

Figure 8: The effect of $w_{\mathrm{s}}$ on AR of the DRA array.

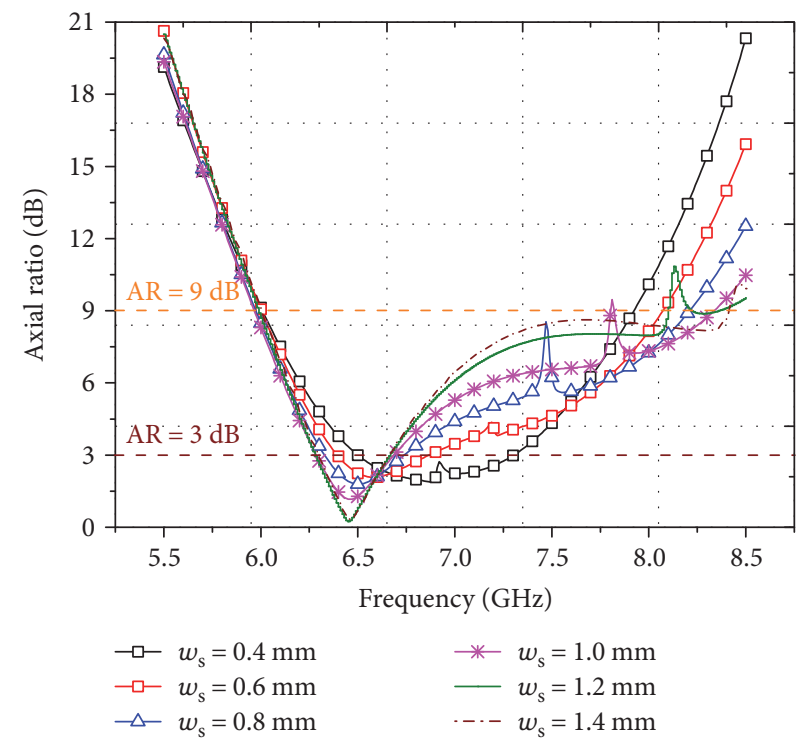

FIGURE 9: The effect of $w_{\mathrm{s}}$ on AR of the array element.

TABLE 1: Optimized parameters of the DRA array.

\begin{tabular}{lccc}
\hline Parameters & Values & Parameters & Values \\
\hline$l_{\mathrm{s} 1}$ & $9.6 \mathrm{~mm}$ & $l_{\mathrm{f} 1}$ & $14 \mathrm{~mm}$ \\
$w_{\mathrm{s}}$ & $1.2 \mathrm{~mm}$ & $l_{\mathrm{f} 2}$ & $4 \mathrm{~mm}$ \\
$k_{\mathrm{s}}$ & 0.6 & $w_{\mathrm{f}}$ & $1.52 \mathrm{~mm}$ \\
$\varphi$ & $45 \mathrm{deg}$ & & \\
\hline
\end{tabular}

frequency. In this situation, the $\mathrm{AR}$ of the array element over the frequency band above $8 \mathrm{GHz}$ is higher than $9 \mathrm{~dB}$. When a larger value of $w_{\mathrm{s}}$ is used, the $3 \mathrm{~dB} \mathrm{AR}$ bandwidth will deteriorate, but a lower AR can be found in the higher 


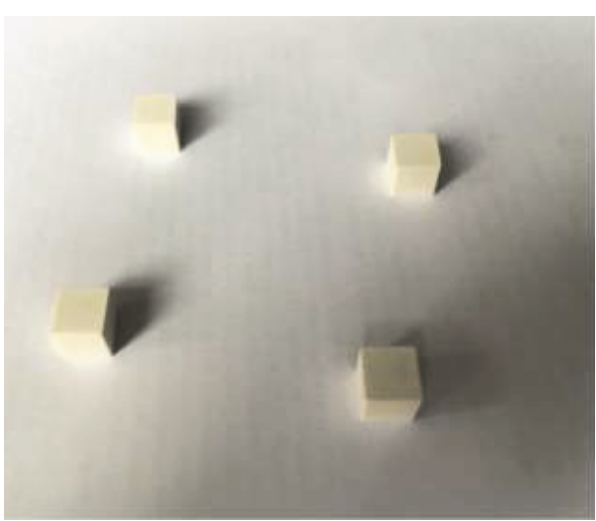

(a)

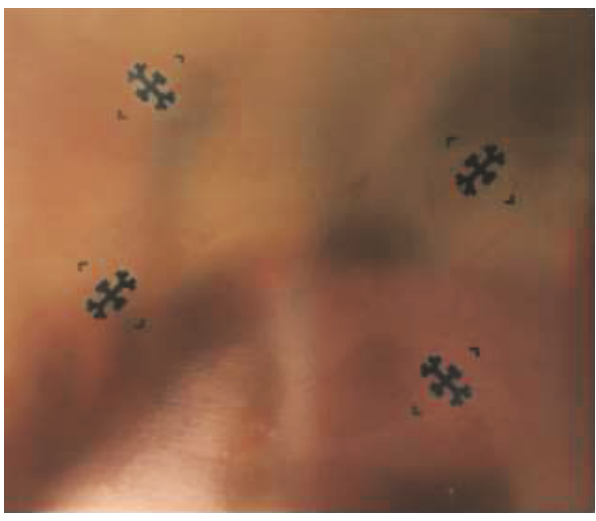

(c)

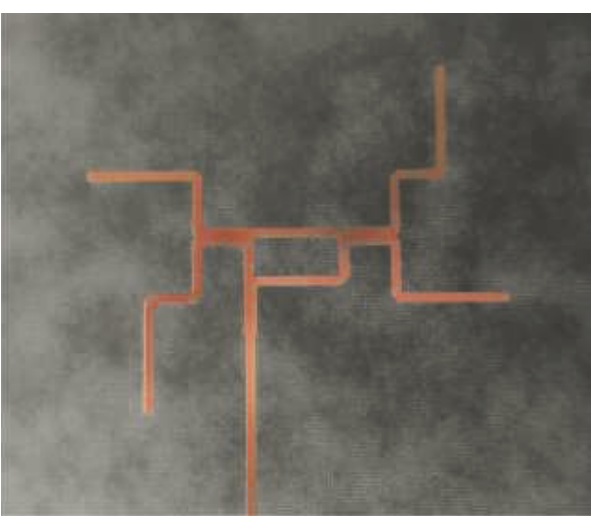

(b)

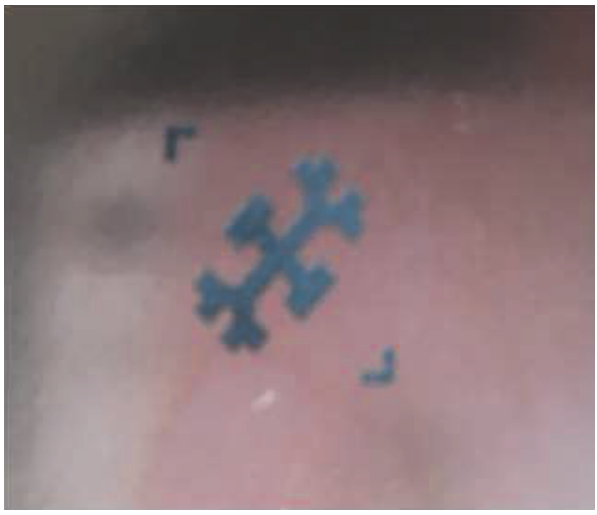

(d)

Figure 10: Photo of the fabricated DRA array. (a) Four DRAs, (b) sequential feeding network, (c) ground plane with slots, and (d) detailed structure of the fractal cross-slot and L-shaped slots.

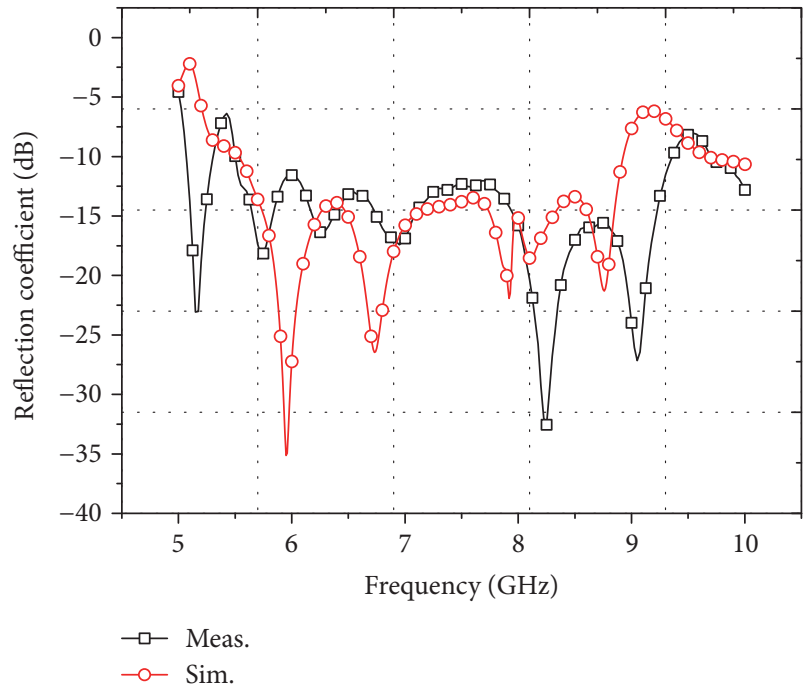

FIgURE 11: Simulated and measured $S_{11}$ of the array.

frequency band. When the value of $w_{\mathrm{s}}$ is larger than $1.0 \mathrm{~mm}$, AR of the array element is basically lower than $9 \mathrm{~dB}$ from 6.0 to $8.5 \mathrm{GHz}$.

Through analyzing, we think that the above interesting phenomenon is due to the intrinsic characteristic of the sequential feeding network. As mentioned before, the

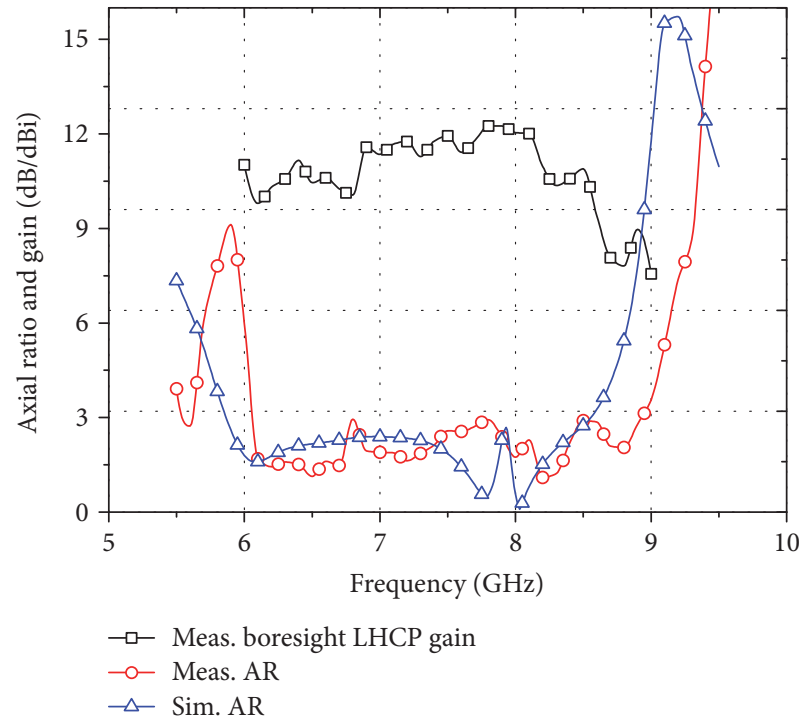

FIGURE 12: Simulated/measured AR and measured boresight LHCP gain of the array.

sequential feeding technique can be used to generate $\mathrm{CP}$ array with LP elements, which means that the sequential feeding network can be used to lower the AR of the array element. For example, assume that AR of an array element 


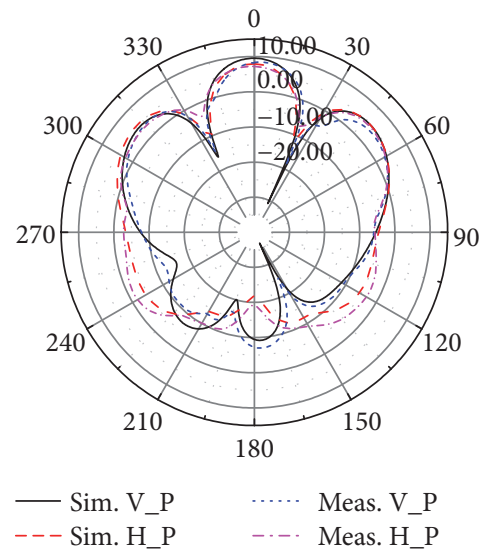

(a)

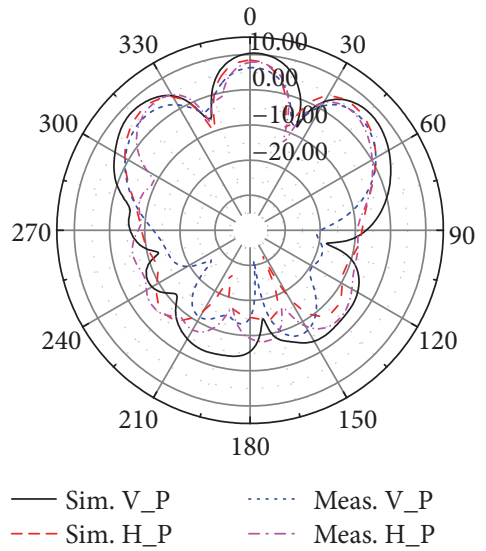

(b)

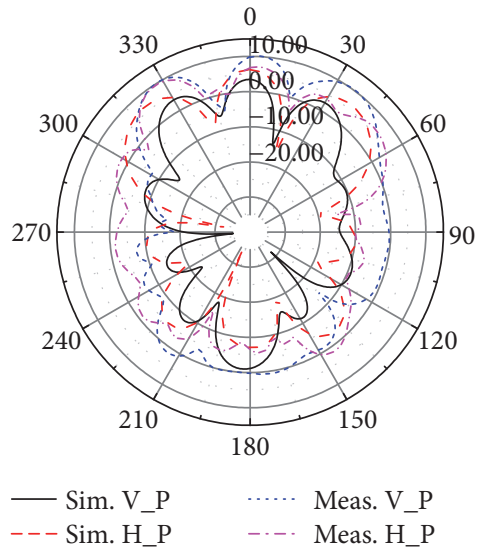

(c)

FIGURE 13: Simulated and measured radiation patterns with vertical and horizontal polarization in $x-z$ plane. (a) $6.5 \mathrm{GHz},(\mathrm{b}) 7.5 \mathrm{GHz}$, and (c) $8.5 \mathrm{GHz}$.

at frequency $f_{0}$ is $\mathrm{AR}_{0}$, if we use the sequential feeding technique to structure an array, the corresponding $\mathrm{AR}$ of the array at the same frequency $f_{0}$ should be lower than $\mathrm{AR}_{0}$. So, if we want to obtain the widest $3 \mathrm{~dB}$ AR bandwidth in the DRA array, we can use another value of $A R\left(A R^{\prime}\right)$ as the design objective in the design of the array element, and $\mathrm{AR}^{\prime}$ should be higher than $3 \mathrm{~dB}$.

Comparing the results in Figures 8 and 9, we can find that, considering the frequency band from 6.0 to $8.5 \mathrm{GHz}$, once the AR of the array element at a particular frequency $\left(f_{0}\right)$ is not higher than $9 \mathrm{~dB}$, the corresponding $\mathrm{AR}$ of the DRA array at the same frequency $f_{0}$ can be lowered to below $3 \mathrm{~dB}$ by the sequential feeding network. So, even though $w_{\mathrm{s}}=0.4 \mathrm{~mm}$ can lead the widest $3 \mathrm{~dB} \mathrm{AR}$ bandwidth in the array element, the larger value of $w_{s}$ can lead a wider $9 \mathrm{~dB}$ AR bandwidth in the array element, which can finally lead a wider $3 \mathrm{~dB}$ AR bandwidth in the DRA array. Finally, we select $w_{\mathrm{s}}=1.2 \mathrm{~mm}$ in our design, because in this situation, the widest $3 \mathrm{~dB}$ AR bandwidth can be obtained in the DRA array.

Of course, it must be point out that the above conclusion "once the AR of the array element at a particular frequency $\left(f_{0}\right)$ is not higher than $9 \mathrm{~dB}$, the corresponding $\mathrm{AR}$ of the DRA array at the same frequency $f_{0}$ can be lowered to below $3 \mathrm{~dB}$ " is not obtained by theoretical analysis or computation, but by the comparison of results in Figures 8 and 9. However, even though it is not a quantitative conclusion, we think that it is a correct qualitative conclusion, which can have a guiding significance in the design of antenna arrays.

3.3. Simulated and Measured Results. In our design, parameters of the DRA array are optimized by HFSS, and all optimized parameters of the array are shown in Table 1.

The proposed wideband CP DRA array is fabricated and measured, and the photo of the fabricated array is shown in Figure 10. To mount the dielectric resonator properly, two extra L-shaped slots are etched around the fractal cross-slot which can show an accurate position of the rectangular dielectric resonator, and by simulation, we ensure that such extra structure will not affect the performance of the array.

Figure 11 is the $S_{11}$ of the proposed DRA array. The simulated impedance bandwidth is $46.5 \%$ (from 5.54 to $8.90 \mathrm{GHz}$ ), and the measured one is $51.5 \%$ (from 5.52 to $9.35 \mathrm{GHz}$ ). According to Figure 11, the measured result has a wider impedance bandwidth than the simulated one due to a better impedance matching over the frequency band above $9.0 \mathrm{GHz}$.

The standard linearly polarized horn antennas are employed for radiation measurements. The simulated and measured boresight ARs of the array are shown in Figure 12. The simulated $3 \mathrm{~dB}$ AR bandwidth is $37.7 \%$ (from 5.84 to $8.55 \mathrm{GHz}$ ), and the measured one is $38.3 \%$ (from 6.06 to $8.93 \mathrm{GHz}$ ). A good agreement is obtained between the simulated and measured ARs, except for about $300 \mathrm{MHz}$ shift between the simulated and measured results. The measured boresight LHCP gain of the array is also shown in Figure 12. Across most of the $3 \mathrm{~dB}$ AR bandwidth, the measured boresight LHCP gain is higher than $10 \mathrm{dBi}$ (from 6.06 to $8.51 \mathrm{GHz}$ ), and a highest $12.17 \mathrm{dBi}$ gain is found at $7.9 \mathrm{GHz}$.

The simulated and measured radiation patterns with vertical and horizontal polarization at $6.5 \mathrm{GHz}, 7.5 \mathrm{GHz}$, and $8.5 \mathrm{GHz}$ in $x-z$ plane are shown in Figure 13. Over the lower frequency band, the patterns are stable, and symmetric radiation can be found in the broadside directions. Moreover, good agreements are obtained between the simulated and measured results at $6.5 \mathrm{GHz}$ and $7.5 \mathrm{GHz}$. When frequency increases to $8.5 \mathrm{GHz}$, about $5^{\circ}$ beam tilt can be found in the measured pattern. Compared with the simulated result, a higher gain can also be found at $8.5 \mathrm{GHz}$, as well as a higher back-lobe level.

3.4. Comparisons. Table 2 gives the comparisons of the proposed DRA array to other reported wideband CP DRA arrays. It can be seen that the proposed DRA array in this paper can provide a wider effective AR bandwidth than others. It is necessary to point out that the sequential feeding 
TABLE 2: Comparisons to other reported DRAAs.

\begin{tabular}{|c|c|c|c|c|c|}
\hline Reference & Yang et al. [3] & Pang et al. [13] & Akbari et al. [14] & Rana and Parui [19] & This work \\
\hline Type of array element & $\begin{array}{c}\text { Rectangular-slot } \\
\text { coupled elliptical } \\
\text { DRA }\end{array}$ & $\begin{array}{c}\text { Cross-slot } \\
\text { coupled-cylindrical } \\
\text { DRA }\end{array}$ & $\begin{array}{l}\text { Cross-slot-coupled } \\
\text { rectangular DRA }\end{array}$ & $\begin{array}{l}\text { Microstrip line-fed } \\
\text { rectangular DRA } \\
\text { (dual feeds) }\end{array}$ & $\begin{array}{c}\text { Fractal cross-slot- } \\
\text { coupled rectangular } \\
\text { DRA }\end{array}$ \\
\hline Type of feeding network & $\begin{array}{c}\text { Sequential feeding } \\
\text { network }\end{array}$ & $\begin{array}{l}\text { Parallel feeding } \\
\text { network }\end{array}$ & $\begin{array}{l}\text { Sequential feeding } \\
\text { network }\end{array}$ & $\begin{array}{l}\text { Series feeding } \\
\text { network }\end{array}$ & $\begin{array}{c}\text { Sequential feeding } \\
\text { network }\end{array}$ \\
\hline Experiment verification & Yes & Yes & No & Yes & Yes \\
\hline Element number & $2 \times 2$ & $2 \times 2$ & $2 \times 2$ & $1 \times 4$ & $2 \times 2$ \\
\hline Impedance bandwidth & $43.9 \%$ & $19 \%$ & $48.31 \%$ & $17 \%$ & $51.5 \%$ \\
\hline $3 \mathrm{~dB}$ axial ratio bandwidth & $26.1 \%$ & $16 \%$ & $21.67 \%$ & $10 \%$ & $38.3 \%$ \\
\hline Effective AR bandwidth & $26.1 \%$ & $16 \%$ & $21.67 \%$ & $10 \%$ & $38.3 \%$ \\
\hline Peak gain & About $12 \mathrm{dBi}$ & About $12 \mathrm{dBi}$ & $12.6 \mathrm{dBi}$ & $13.6 \mathrm{dBi}$ & $12.17 \mathrm{dBi}$ \\
\hline
\end{tabular}

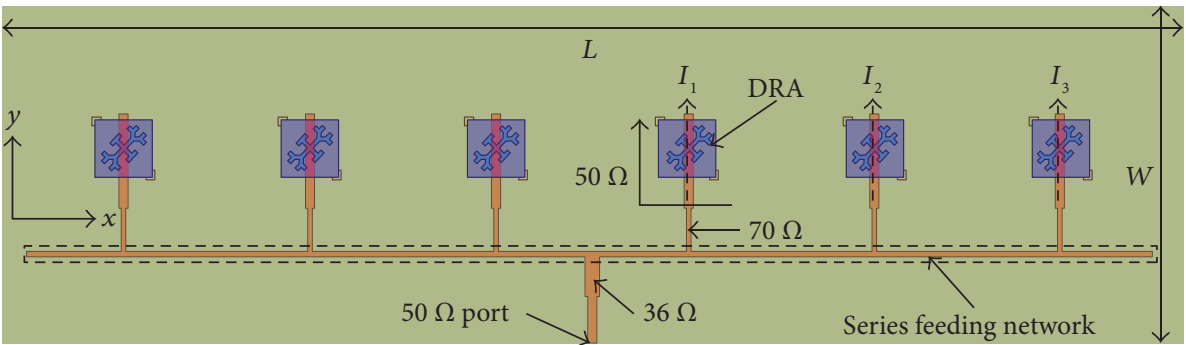

FIGURE 14: Structure of the proposed low-sidelobe-level CP DRA array.

technique and the corresponding hybrid ring feeding network are all used in $[3,14]$, and this design. So, we can ensure that it is the structure of fractal cross-slot and the careful parameter optimization that provide a wider effective AR bandwidth in our design.

\section{Design of the Low-Sidelobe-Level CP DRA Array}

In recent years, more and more attentions have been paid to the design of low-sidelobe-level DRA arrays. In [15], lowsidelobe-level DRA array fed by dielectric insular image guide (DIIG) is investigated. In [16], slot windows and reflector are used in the design of DRA array. In [17], DRA array with parasitic DRA elements is proposed. However, it seems that most of the designs mentioned in this paper are either on generating circular polarization or suppressing the SLL of DRA array, but not both.

In this paper, a low-sidelobe-level CP DRA array is also designed based on the proposed fractal cross-slot-coupled array element, which can be another verification of the proposed DRA element.

4.1. Antenna Structure. Figure 14 shows the structure of the designed $1 \times 6$ low-sidelobe-level CP DRA array. In this design, we rotate all slots to $90^{\circ}$ to generate the righthanded circularly polarized (RHCP) radiation. Six ceramic cubes are mounted on a substrate with length $L=206 \mathrm{~mm}$ and width $W=59 \mathrm{~mm}$. The proposed DRA array is designed to operate at $7.0 \mathrm{GHz}$ with a $-20 \mathrm{~dB}$ SLL. To achieve such
TABle 3: Optimized parameters of the DRA array.

\begin{tabular}{lccc}
\hline Parameters & Values & Parameters & Values \\
\hline$l_{\mathrm{s} 1}$ & $9.7 \mathrm{~mm}$ & $l_{\mathrm{f} 1}$ & $10 \mathrm{~mm}$ \\
$w_{\mathrm{s}}$ & $0.5 \mathrm{~mm}$ & $l_{\mathrm{f} 2}$ & $5.8 \mathrm{~mm}$ \\
$k_{\mathrm{s}}$ & 0.59 & $w_{\mathrm{f}}$ & $1.52 \mathrm{~mm}$ \\
$\varphi$ & $50 \mathrm{deg}$ & & \\
\hline
\end{tabular}

goal, a Chebyshev amplitude distribution and the corresponding series feeding network are used. To achieve a $-20 \mathrm{~dB}$ SLL, the current ratios of the 6-element Chebyshev array is $I_{1}: I_{2}: I_{3}=1: 0.777: 0.551$. Details of series feeding network designs and analyses can be found in [18].

When the series feeding network is used, we need to adjust the input impedance of the array element to get $50 \Omega$ input impedance in the sum port of the DRA array. In our design, the required input impedance of the array element is $190 \Omega$. To reduce the discontinuity of the width of the microstrip line in the feeding network, two $\lambda / 4$ lines are used for impedance conversion in our design. Firstly, the $70 \Omega$ microstrip line is used between the array element and series feeding network, which can convert the input impedance of the array element to $98 \Omega$. Thus, the input impedance in the sum port becomes $25.85 \Omega$. So, another $36 \Omega$ microstrip line is used to get the $50 \Omega$ input impedance in the sum port.

The parameters of the DRA array are optimized by HFSS, and the final results are shown in Table 3. Different from the sequential feeding network, the series feeding network has no 


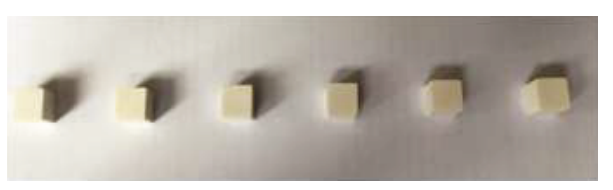

(a)

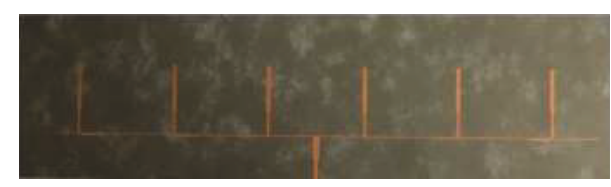

(b)

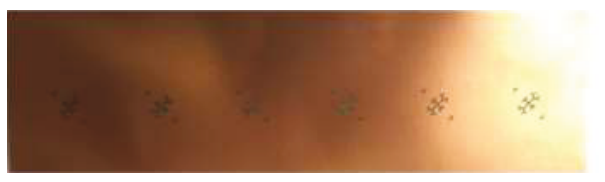

(c)

FIgURE 15: Photo of fabricated DRA array. (a) Six DRAs, (b) series feeding network, and (c) ground plane with slots.

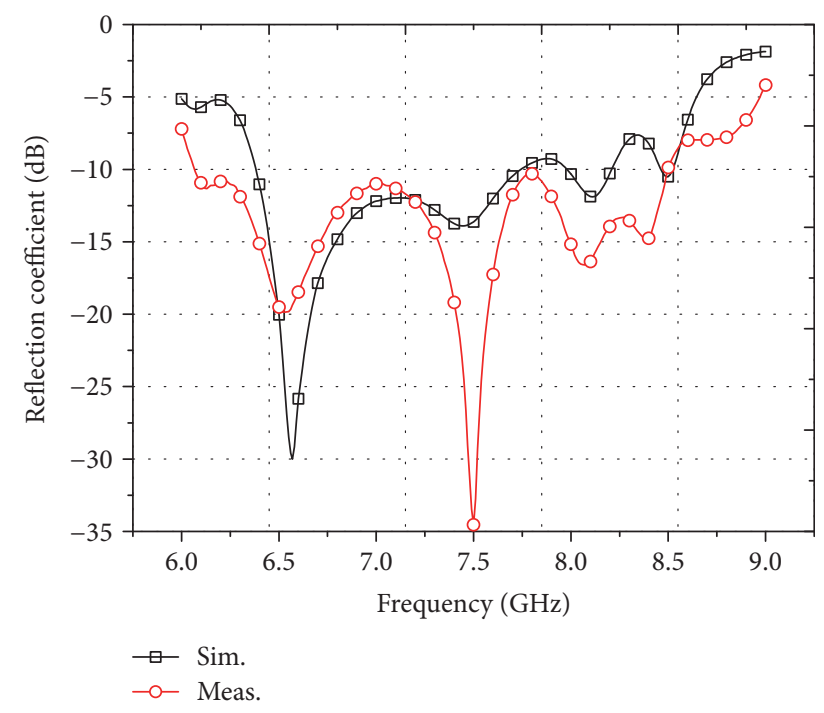

FIgURE 16: Simulated and measured $S_{11}$ of the array.

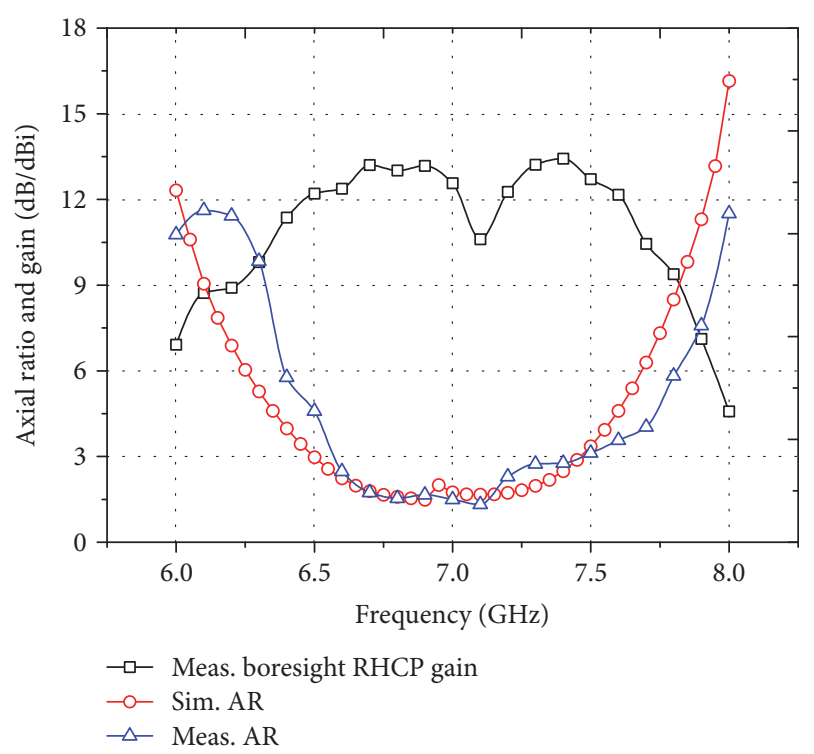

FIGURE 17: Simulated/measured AR and measured boresight RHCP gain of the array.

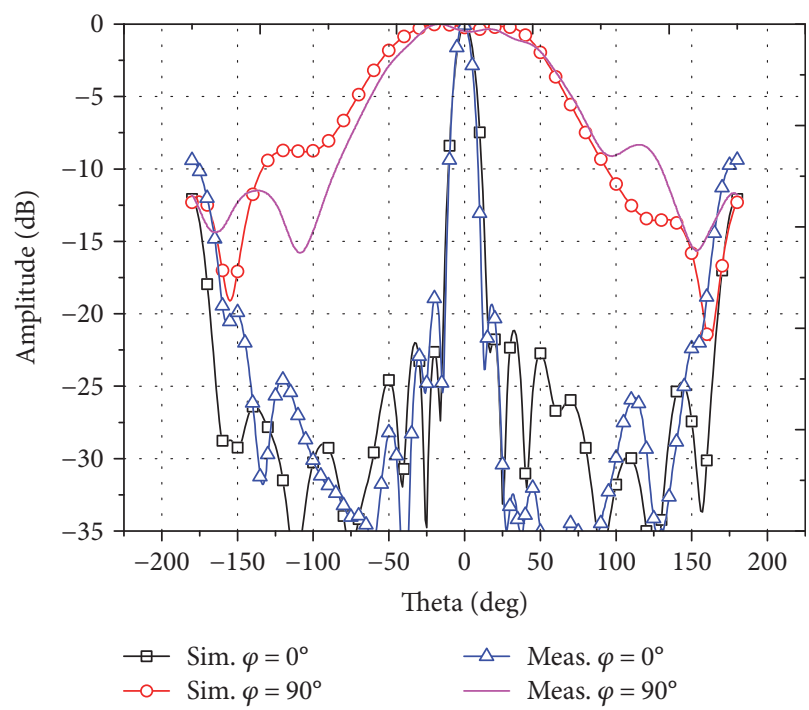

FIGURE 18: Simulated and measured normalized radiation pattern of the array at $7.0 \mathrm{GHz}$.

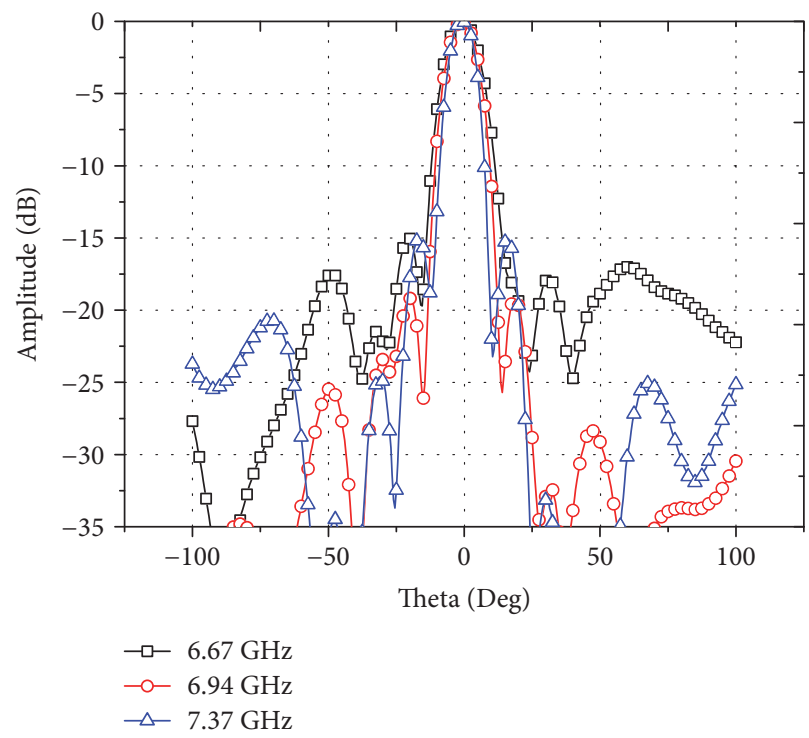

FIGURE 19: Measured normalized radiation patterns of the array at 6.67 GHz, $6.94 \mathrm{GHz}$, and $7.37 \mathrm{GHz}$. 
TABLE 4: Comparisons to other reported low-sidelobe-level DRA arrays.

\begin{tabular}{|c|c|c|c|c|c|}
\hline Reference & Jin et al. [15] & Lin et al. [16] & Nikkhah et al. [17] & Gupta et al. [20] & This work \\
\hline Type & $\begin{array}{l}\text { DRA array } \\
\text { using DIIG }\end{array}$ & $\begin{array}{l}\text { Series microstrip } \\
\text { feeding network }\end{array}$ & $\begin{array}{l}\text { Series microstrip } \\
\text { feeding network }\end{array}$ & $\begin{array}{l}\text { Parallel substrate } \\
\text { integrated waveguide }\end{array}$ & $\begin{array}{l}\text { Series microstrip } \\
\text { feeding network }\end{array}$ \\
\hline Experiment verification & Yes & Yes & No & No & Yes \\
\hline Element number & $2 \times 10$ & $1 \times 8$ & $2 \times 8$ & $1 \times 8$ & $1 \times 6$ \\
\hline Impedance bandwidth & $>28.6 \%$ & $38.1 \%$ & $22.4 \%$ & $13.3 \%$ & $33.1 \%$ \\
\hline Design objective of SLL & $-20 \mathrm{~dB}$ & $-25 \mathrm{~dB}$ & $-24 \mathrm{~dB}$ & Not given & $-20 \mathrm{~dB}$ \\
\hline Obtained SLL & $-17.5 \mathrm{~dB}$ & $-23.01 \mathrm{~dB}$ & $-22.6 \mathrm{~dB}$ & $-21.4 \mathrm{~dB}$ & $-19.23 \mathrm{~dB}$ \\
\hline Peak gain & $15.8 \mathrm{dBi}$ & $15.7 \mathrm{dBi}$ & $17.4 \mathrm{dBi}$ & $13.41 \mathrm{dBi}$ & $13.43 \mathrm{dBi}$ \\
\hline $3 \mathrm{~dB}$ axial ratio bandwidth & & & & & $12.4 \%$ \\
\hline
\end{tabular}

effect on AR, so it can be found that the optimized value of $w_{\mathrm{s}}$ in Table 3 is close to the optimized value in array element.

4.2. Simulated and Measured Results. The proposed DRA array is fabricated and measured, and a photo of the array is shown in Figure 15.

Figures 16 and 17 show the $S_{11}$, AR, and boresight RHCP gain of the array. The simulated and measured impedance bandwidths of the array are $18.1 \%$ (from 6.38 to $7.65 \mathrm{GHz}$ ) and $33.1 \%$ (from 6.07 to $8.48 \mathrm{GHz}$ ), respectively. The simulated $3 \mathrm{~dB} \mathrm{AR}$ bandwidth is $13.9 \%$ (from 6.51 to $7.48 \mathrm{GHz}$ ), and the measured one is $12.4 \%$ (from 6.58 to $7.45 \mathrm{GHz}$ ). Due to a better impedance matching over the frequency band from 7.8 to $8.5 \mathrm{GHz}$, the measured impedance is much wider than the simulated one. However, it is obvious that the real performance of DRA array will be subject to the measured $3 \mathrm{~dB}$ AR bandwidth, which is $1.5 \%$ narrower than the simulated AR bandwidth. Across the measured $3 \mathrm{~dB}$ AR bandwidth, the boresight RHCP gain of the array is about $12.5 \mathrm{dBi}$, except a lowest measured RHCP gain around $7.1 \mathrm{GHz}$ (about $10.0 \mathrm{dBi}$ ), and the highest measured RHCP gain is $13.43 \mathrm{dBi}$ at $7.4 \mathrm{GHz}$.

Figures 18 and 19 are the normalized radiation patterns of the array. It is necessary to point out that all data in Figures 18 and 19 are based on the total gain of the DRA array. As mentioned above, two standard linearly polarized horn antennas are employed for radiation measurements, so the measured results of radiation pattern consist of two parts: the vertical polarized gain $G_{\mathrm{V}}$ and the horizontal polarized gain $G_{\mathrm{H}}$, and the corresponding total gain can be computed by

$$
G_{\text {total }}=10 \lg \left(10^{G_{\mathrm{H}} / 10}+10^{G_{\mathrm{V}} / 10}\right) .
$$

Figure 18 shows the normalized radiation patterns of the array at $7.0 \mathrm{GHz}$. The simulated SLL in $x-z$ plane $\left(\varphi=0^{\circ}\right)$ is about $-21 \mathrm{~dB}$, which is lower than our design target. Of course, we think that such result is derived from the errors in simulation. The measured SLL at $7.0 \mathrm{GHz}$ is $-18.72 \mathrm{~dB}$, which is very close to the design target.

As shown in Figure 19, the frequency band over which SLL $<-15 \mathrm{~dB}$ is found to be from 6.67 to $7.37 \mathrm{GHz}$, which is 9.97\%. As mentioned above, over such frequency band $(\mathrm{SLL}<-15 \mathrm{~dB}), S_{11}<-10 \mathrm{~dB}$ and $\mathrm{AR}<3 \mathrm{~dB}$ can also be satisfied. The lowest measured SLL of $-19.23 \mathrm{~dB}$ happens at $6.94 \mathrm{GHz}$.

4.3. Comparisons. Because no reported results of lowsidelobe-level CP DRA arrays are found, we present the comparisons of the proposed array to other reported low-sidelobe-level and wideband DRA arrays (LP arrays) in recent years in Table 4. The proposed low-sidelobe-level CP DRA array shows a wider impedance bandwidth than other designs (except [16], in which the slot windows and reflector are used), and the minor difference between the expected SLL and the obtained SLL can show a successful suppression of sidelobe. Of course, compared to our design, higher antenna gain can be found in others. We think the cause of that is the difference in element number. Through the abovementioned comparisons, we believe that our design can be considered as a good design of low-sidelobe-level and wideband DRA array. On this basis, an extra $3 \mathrm{~dB}$ AR bandwidth of $12.4 \%$ can be obtained in our design. Compared with the purely LP arrays, we think that the proposed lowsidelobe-level DRA array with CP characteristic is more attractive and valuable.

\section{Conclusion}

Based on the proposed fractal cross-slot-coupled CP DRA, designs of a wideband CP DRA array and a low-sidelobelevel DRA array are proposed in this paper. Effective AR bandwidth of the proposed wideband CP DRA array is $38.3 \%$ (from 6.06 to $8.93 \mathrm{GHz}$ ), and $12.17 \mathrm{dBi}$ peak gain is obtained. The proposed low-sidelobe-level CP DRA array has an effective AR bandwidth of $12.4 \%$ (from 6.58 to $7.45 \mathrm{GHz}$ ), and a $9.97 \%$ (from 6.67 to $7.37 \mathrm{GHz}$ ) for $-15 \mathrm{~dB}$ SLL bandwidth is obtained. The results of our work show that the proposed fractal cross-slot-coupled DRA element, which has a simple structure without dual feeds or two-layered substrates, is quite suitable for the design of DRA arrays.

\section{Conflicts of Interest}

The authors declare that there are no competing interests regarding the publication of this paper. 


\section{Acknowledgments}

This work was supported by the Natural Science Foundation of China under Grant no. 61171031.

\section{References}

[1] M. Haneishi and H. Takazawa, "Broadband circularly polarised planar array composed of a pair of dielectric resonator antennas," Electronics Letters, vol. 21, no. 10, pp. 437-438, 1985.

[2] J. Huang, "A technique for an array to generate circular polarization with linearly polarized elements," IEEE Transactions on Antennas and Propagation, vol. 34, no. 9, pp. 1113-1124, 1986.

[3] S.-1. S. Yang, R. Chair, A. A. Kishk, K.-F. Lee, and K.-M. Luk, "Study on sequential feeding networks for subarrays of circularly polarized elliptical dielectric resonator antenna," IEEE Transactions on Antennas and Propagation, vol. 55, no. 2, pp. 321-333, 2007.

[4] R.-C. Han, S.-S. Zhong, and J. Liu, "Broadband circularly polarised dielectric resonator antenna fed by wideband switched line coupler," Electronics Letters, vol. 50, no. 10, pp. 725-726, 2014.

[5] K.-W. Khoo, Y.-X. Guo, and L. C. Ong, "Wideband circularly polarized dielectric resonator antenna," IEEE Transactions on Antennas and Propagation, vol. 55, no. 7, pp. 1929-1932, 2007.

[6] G. Massie, M. Caillet, M. Clenet, and Y. M. M. Antar, "A new wideband circularly polarized hybrid dielectric resonator antenna," IEEE Antennas and Wireless Propagation Letters, vol. 9, pp. 347-350, 2010.

[7] M. I. Sulaiman and S. K. Khamas, "A singly fed rectangular dielectric resonator antenna with a wideband circular polarization," IEEE Antennas and Wireless Propagation Letters, vol. 9, pp. 615-618, 2010.

[8] M. Zou, J. Pan, Z. Nie, and P. Li, "A wideband circularly polarized rectangular dielectric resonator antenna excited by a lumped resistively loaded monofilar-spiral-slot," IEEE Antennas and Wireless Propagation Letters, vol. 12, pp. 16461649, 2013.

[9] R. Chair, S. L. S. Yang, A. A. Kishk, K. F. Lee, and K. M. Luk, "Aperture fed wideband circularly polarized rectangular stair shaped dielectric resonator antenna," IEEE Transactions on Antennas and Propagation, vol. 54, no. 4, pp. 1350-1352, 2006.

[10] V. Hamsakutty, A. V. Praveen Kumar, J. Yohannan, and K. T. Mathew, "Coaxial fed hexagonal dielectric resonator antenna for circular polarization," Microwave and Optical Technology Letters, vol. 48, no. 3, pp. 581-582, 2006.

[11] M. Simeoni, R. Cicchetti, A. Yarovoy, and D. Caratelli, "Plastic-based supershaped dielectric resonator antennas for wide-band applications," IEEE Transactions on Antennas and Propagation, vol. 59, no. 12, pp. 4820-4825, 2011.

[12] R. K. Mongia, "Theoretical and experimental resonant frequencies of rectangular dielectric resonators," IEE Proceedings- $H$, vol. 139, no. 1, pp. 98-104, 1992.

[13] K. K. Pang, H. Y. Lo, K. W. Leung, K. M. Luk, and E. K. N. Yung, "Circularly polarized dielectric resonator antenna subarrays," Microwave and Optical Technology Letters, vol. 27, no. 6, pp. 377-379, 2000.

[14] M. Akbari, S. Gupta, R. Movahedinia, and A. R. Sebak, "Comparison of sequential subarrays of circularly polarized DR and patch antennas based on hybrid ring feeding in MMW," in
2016 Progress in Electromagnetics Research Symposium (PIERS), pp. 4009-4012, Shanghai, China, 2016.

[15] L. Jin, R. Lee, and I. Robertson, "A dielectric resonator antenna array using dielectric insular image guide," IEEE Transactions on Antennas and Propagation, vol. 63, no. 2, pp. 859-862, 2015.

[16] J. Lin, W. Shen, and K. Yang, "A low-sidelobe and wideband series-fed linear dielectric resonator antenna array," IEEE Antennas and Wireless Propagation Letters, vol. 16, pp. 513516, 2017.

[17] M. Ranibar Nikkhah, J. Rashed-Mohassel, and A. A. Kishi, "Wide-band and low sidelobe array of rectangular dielectric resonator antennas with parasitic elements," in 2014 International Conference on Multimedia Computing and Systems (ICMCS), pp. 1422-1425, Marrakech, Morocco, 2014.

[18] R. Garg, P. Bhartia, I. Bahl, and A. Ittipiboon, Microstrip Antenna Design Handbook, Artech House, Norwood, MA, USA, 2001.

[19] B. Rana and S. K. Parui, "Microstrip line fed wideband circularly-polarized dielectric resonator antenna array for microwave image sensing," IEEE Sensors Letters, vol. 1, no. 3, 2017.

[20] S. Gupta, M. Akbari, R. Movahedinia, S. Zarbakhsh, and A. R. Sebak, "Low-side lobe level aperture coupled dielectric resonator antenna array fed by SIW," in 2016 10th European Conference on Antennas and Propagation (EuCAP), pp. 1-4, Davos, Switzerland, 2016. 


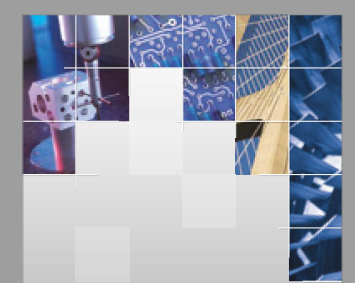

\section{Enfincering}
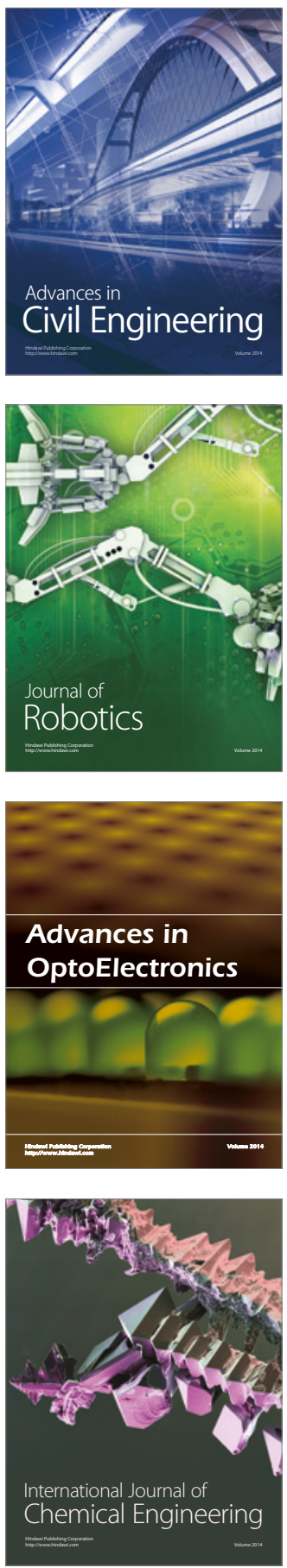

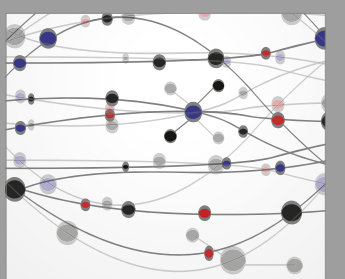

The Scientific World Journal

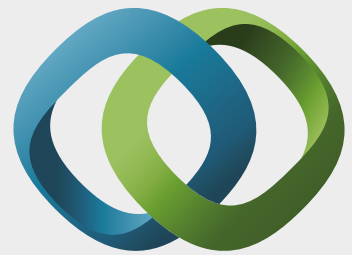

\section{Hindawi}

Submit your manuscripts at

https://www.hindawi.com
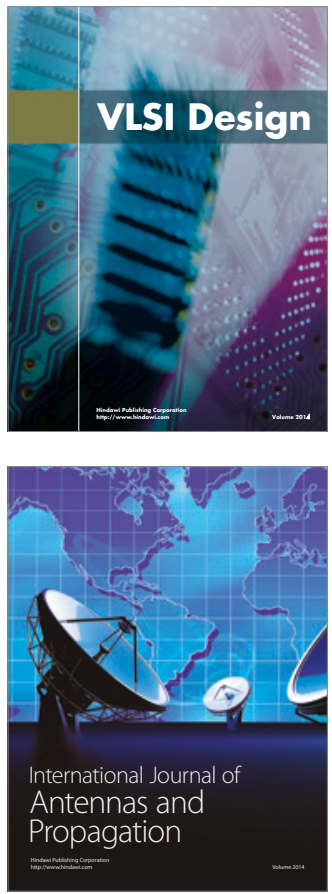

\section{Rotating}

Machinery
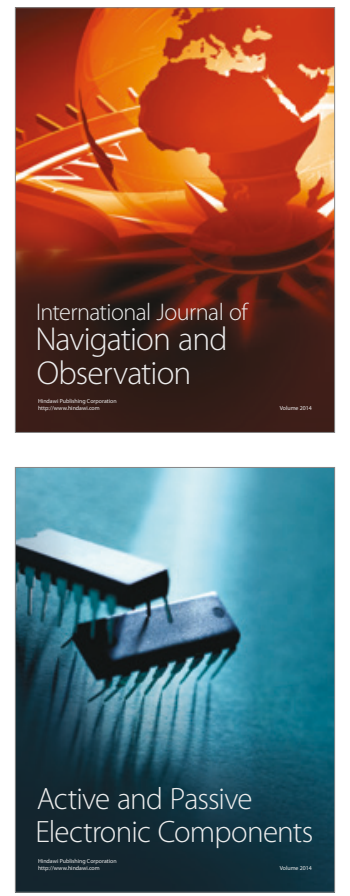
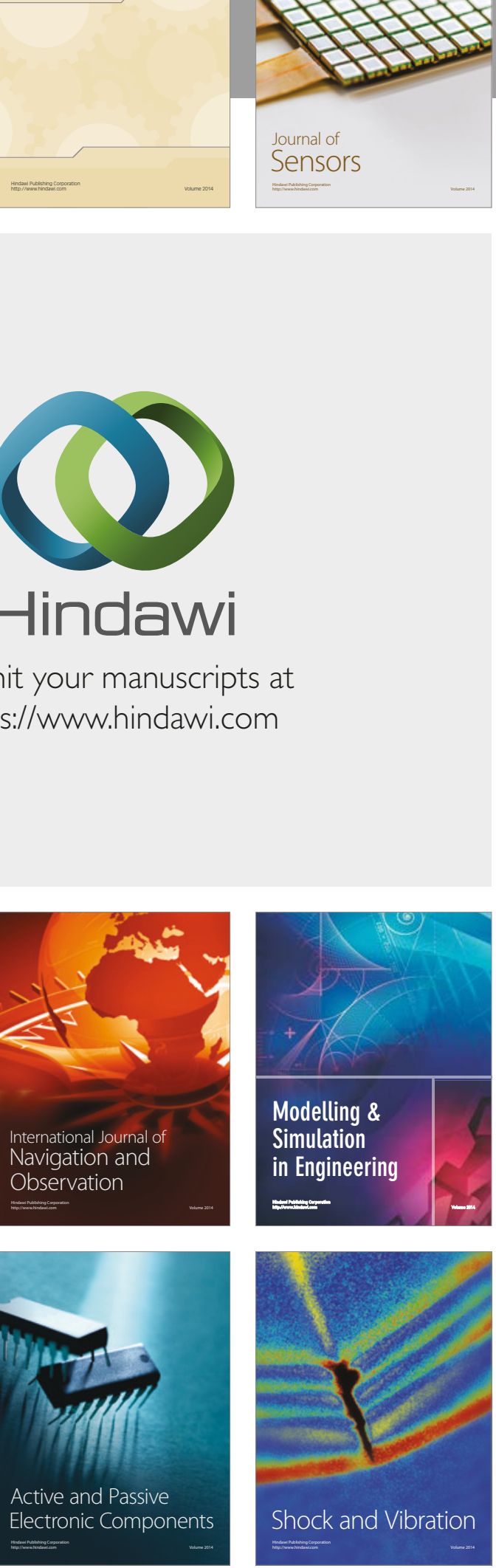
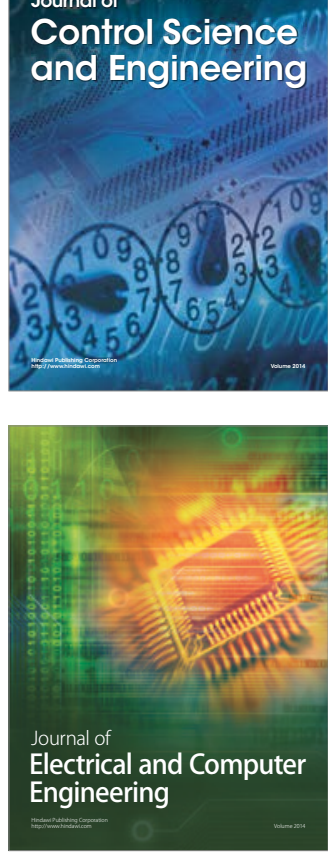

Distributed

Journal of

Control Science

and Engineering
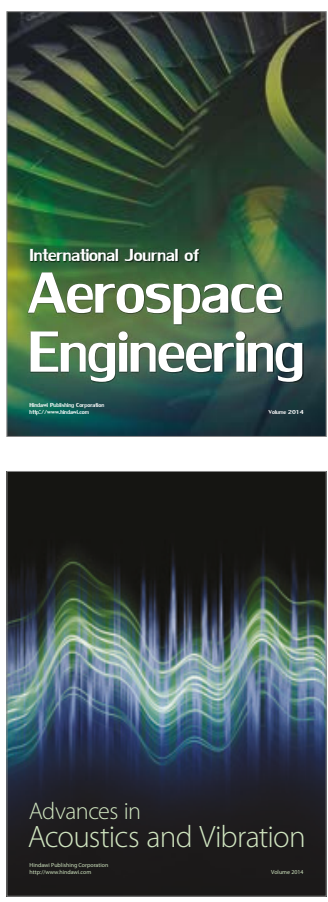

Sensor Networks 